\title{
OCCUPATIONAL RHINITIS IN THE SLOVAK REPUBLIC - A LONG-TERM RETROSPECTIVE STUDY
}

\author{
Slavomír Perečinský ${ }^{1}$, L'ubomír Legáth ${ }^{1}$, Marek Varga ${ }^{1}$, Martin Javorský2, Igor Bátora ${ }^{3}$, Gabriela Klimentová4 \\ ${ }^{1}$ Department of Occupational Medicine and Clinical Toxicology, Medical Faculty, P. J. Šafárik University, Košice, Slovakia \\ 2Department of Internal Medicine 4, Medical Faculty, P. J. Šafárik University, L. Pasteur University Hospital, Košice, Slovakia \\ ${ }^{3}$ Department of Occupational Medicine and Toxicology, Faculty of Medicine in Bratislava, Comenius University in Bratislava, Bratislava, Slovakia \\ ${ }^{4}$ Department of Occupational Medicine and Toxicology, Jessenius Faculty of Medicine in Martin, Comenius University in Bratislava, Martin, Slovakia
}

\section{SUMMARY}

Background: Allergic and non-allergic rhinitis ranks among the common occupational health problems. However, data on the incidence of occupational rhinitis are lacking, since comprehensive studies are rare.

Methods: The study includes a group of patients in the Slovak Republic who were reported as having occupational rhinitis in the years 1990-2011. The following parameters were tracked in the investigated sample: age, gender, number of cases by individual years, occupations, causative factors and the length of exposure to the given agent. Possible progression of rhinitis to bronchial asthma was evaluated as well. The diagnostic algorithm was also analysed retrospectively, which included skin tests, the examination of specific IgE antibodies and nasal provocation tests.

Results: A total of 70 cases of occupational rhinitis were reported. The disease most often occurred in food industry workers (50\% of cases). The most common aetiological factor was flour. Among other relatively common allergens were synthetic textile, wool, cotton and different types of moulds. Significant agents were also different chemical factors causing allergic and irritant rhinitis. The average length of exposure was 14.8 years. Exposure was shorter in men than in women (11 years vs. 16 years) $(p=0.04)$. Bronchial asthma as a comorbidity was diagnosed in 13 patients (19.7\%). The critical diagnostic method on the basis of which the causal association between rhinitis and work environments was confirmed in $59 \%$ of cases was skin test; confirmation of the occupational cause using nasal provocation test was less frequent (18\%).

Conclusion: Food industry, textile industry and agriculture were the most risky occupational environments. Workers in these sectors require preventive intervention. In case of showing rhinitis symptoms it is necessary to confirm the occupational aetiology of the disease by the objective diagnostic methods. Since occupational rhinitis mostly precedes the occupational asthma, the elimination from the workplace is necessary.

Key words: occupational rhinitis, asthma, risky occupations, allergens, nasal provocation test

Address for correspondence: S. Perečinský, Department of Occupational Medicine and Clinical Toxicology, Medical Faculty, P. J. Šafárik University, and the L. Pasteur University Hospital, 04190 Košice, Slovakia. E-mail: slavomir.perecinsky@upjs.sk

\section{INTRODUCTION}

"Occupational rhinitis (OR) is an inflammatory disease of the nose which is characterised by intermittent or persistent symptoms (nasal congestion, sneezing, rhinorrhea, itching), and/or variable nasal airflow limitation and/or hypersecretion due to causes and conditions attributable to a particular work environment and not to stimuli encountered outside the workplace” (1). At present, it belongs to the most common occupational diseases of the airways, and it occurs 2-4 times more often than occupational asthma (OA) (2), though occupational asthma is more often diagnosed disease than OR. In the last years, there have been published several guidelines and review articles concerning OR (1, 3-5). However, the prevalence and incidence of occupational rhinitis has almost never been specifically researched (6). Studies relating to evaluations of the aetiology and risk of the occurrence of occupational rhinitis are relatively rare $(7,8)$. Case-based or epidemiological studies from the same workplace have been predominately published (9-14). For these reasons it is relatively complicated to obtain an overall view of the epidemiology of occupational rhinitis.

Despite the fact that rhinitis is a common occupational health problem it is rarely acknowledged as an occupational disease in Slovakia. One reason is the insufficient diagnostics in view of the absence of standard diagnostic methods in several countries.

OR is not only domain of occupational medicine but is also related to several branches of medicine. Financial compensation depends on the decision of social insurance authorities. Furthermore, the diagnostics of the disease as well as the decision of the insurer is determined by the relevant legislation.

The presented study includes cases of occupational rhinitis in Slovakia with the goal of determining the most endangered professions and the most common causative factors. One component of the study is also an overview of the most commonly used methods for diagnostics of occupational rhinitis.

\section{MATERIALS AND METHODS}

The study included patients diagnosed with occupational rhinitis in the Slovak Republic in the years 1990-2011. Patients were identified by review of patients' databases in clinics and ambulances of occupational medicine in all Slovak regions.

In this study we followed age, gender, total number of cases during the monitored period by individual years, occupations, causative factors, and the length of exposure to the agent. In addition, the possible progression of rhinitis to bronchial asthma was also analyzed. 
The diagnostic algorithms used in the individual regions of Slovakia were also searched retrospectively. In the majority of patients the suspected occupational allergens were tested using skin tests, examination of specific IgE antibodies was performed or both methods were employed simultaneously. Sensitivity to common inhalation allergens was also tested. Skin tests were performed as "prick" tests or by the intradermal method.

In 12 patients a nasal provocation test (NPT) was performed at the departments of occupational medicine (putting the paper disc impregnated by allergen on nasal mucosa) or directly in the workplace according to the published method $(15,16)$.

A condition for reporting an occupational disease was the otorhinolaryngologist-verifed occurrence of rhinitis and the results of an immunoallergological examination and nasal provocation and exposure tests. Another condition was the hygienic survey with verification of presence of agents in the work environment.

Prior to the year 2004, the disease was reported under the item of national law “Other impairment of health", and after 2004 under item 45 - "Allergic diseases of the upper respiratory tracts with hypersensitivity to allergens present in the working environment" (list of Occupational Diseases).

\section{RESULTS}

In the years 1990-2011, a total of 70 cases of OR were reported in the Slovak Republic. In the study 66 patients were monitored further, and data on 4 patients were unavailable. The sample consisted of 45 women and 21 men. The average age at the time of reporting the occupational disease was 39 years: 41 years of age in women and 36 years of age in men. In women the number of cases increased with increasing age. By contrast, among men a decline in the number of cases was recorded in the higher age groups.

Throughout the monitored period the number of cases in the individual years was permanently low. However, a moderately rising trend was recorded, particularly in the last years (Fig. 1).

OR most often occurred in workers in the food industry (50\% of cases) (Table 1). From these, most cases were bakers, and then packagers of flour, pastas and pastry chefs (data not shown).

The most frequent aetiological agent was flour, predominately wheat or rye flour either as an isolated allergen or as a mixture of flours together with mill dust (Table 2). Among other relatively

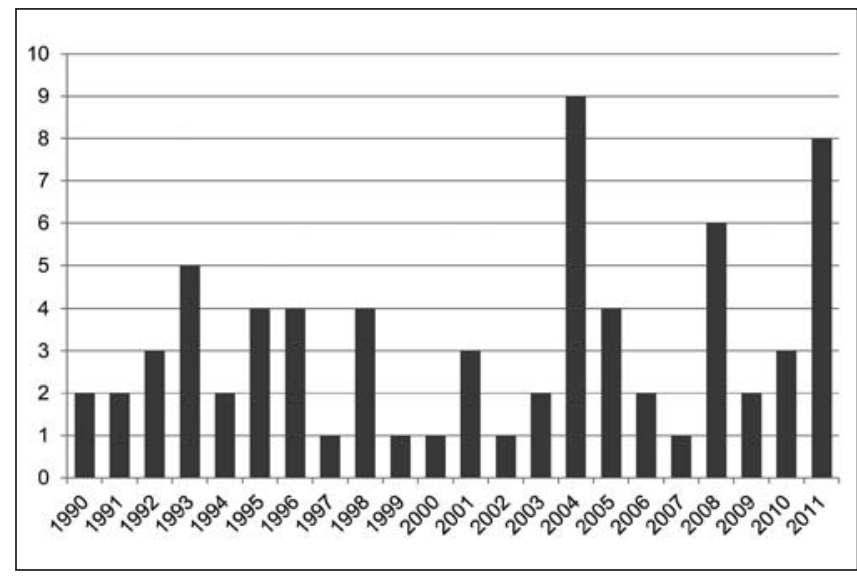

Fig. 1. Number of reported cases of OR by individual years.

Table 1. Representation of individual professions
\begin{tabular}{|l|c|}
\hline Sector & Percent of cases (\%) \\
\hline Food industry & 50 \\
\hline Textile industry & 17 \\
\hline Agriculture & 8 \\
\hline Healthcare industry & 6 \\
\hline Raw mineral extraction & 6 \\
\hline Leather industry & 5 \\
\hline Machining & 4 \\
\hline Chemical industry & 3 \\
\hline
\end{tabular}

frequently reported allergens were synthetic textile, wool, cotton (often in combination in one patient) and different types of moulds. Different chemical factors were also significant agents causing allergic and irritated rhinitis: formaldehyde (2 cases), isopropylalcohol, sulphuric acid fumes, terephthalates, cement, glues and peracetic acid (all agents in 1case). Other factors, including pollen, occurred only rarely.

The average length of exposure was 14.8 years (in a range of 0.5-39 years). Exposure was significantly shorter in men than in women (11 years vs. 16 years) $(p=0.04)$. Bronchial asthma was diagnosed at the time of reporting occupational rhinitis or later in 13 patients (19.7\%).

The diagnostic methods used, aside from otorhinolaryngological examination, included skin tests, examination of IgE antibodies and in some cases nasal provocation test (NPT), as can be seen in Table 3. Causality between OR and occupational environment was supported by skin tests (prick or intradermal) in $59 \%$ subjects. Confirmation of occupational disease using NPT was less common, as was diagnostics on the basis of only

Table 2. Aetiological factors in subject with OR

\begin{tabular}{|l|c|}
\hline Aetiological factor & Count \\
\hline Wheat flour & 23 \\
\hline Rye flour & 16 \\
\hline Other food allergies & 5 \\
\hline Mill dust & 4 \\
\hline Cotton & 9 \\
\hline Wool & 6 \\
\hline Synthetic material & 7 \\
\hline Latex & 2 \\
\hline Leather & 1 \\
\hline Dust mites & 3 \\
\hline Pollen & 2 \\
\hline Animal dander & 1 \\
\hline Tobacco dust & 1 \\
\hline Chemicals & 9 \\
\hline Moulds & 6 \\
\hline Bacterial mixture & 1 \\
\hline Cold & 1 \\
\hline Total & 97 \\
\hline
\end{tabular}


Table 3. Critical diagnostic method

\begin{tabular}{|l|c|}
\hline Diagnostic method & Number of subjects \\
\hline Skin prick or intradermal tests & 39 \\
\hline Specific lgE antibodies & 12 \\
\hline NPT by disc method & 10 \\
\hline NPT in the workplace & 2 \\
\hline Confirmation OR without any objective method & 3 \\
\hline
\end{tabular}

NPT - Nasal provocation test

otorhinolaryngological diagnosis together with a case-history of symptoms without a standard allergological examination.

\section{DISCUSSION}

A long-term retrospective study analyzes cases of occupational rhinitis in Slovakia.

More cases were found in women than in men. In women a rising trend was recorded with increasing age, while in men the disease occurred more often at a lower age. These data are in accordance with the findings of Finnish authors (8).

The total number of reported cases of occupational rhinitis over a relatively long period was low, but with a moderate increase in recent years. This can be associated with the classification of occupational rhinitis and its inclusion in the List of Occupational Diseases of the Slovak Republic after 2003 and with the worldwide new perception of allergic rhinitis $(17,18)$.

Most common risk of OR was in the food industry (50\% of all cases). In addition to food allergens, the most common aetiological factor was flour. The most commonly affected profession were bakers, as it was confirmed in other study, where bakers constituted up to $83 \%$ of cases, and in others occupations like millers and pastry cooks the incidence of the disease was significantly lower (19). The authors explain this by the fact that in addition to different types of flour, bakers are also exposed to additive fungal amylase (obtained from Aspergillus oryzae). Fungal amylase could be an aetiological agent more often than flour (19), as was documented in the work of Cullinan et al. (20) and Smith and Lumley (21). Other aetiological factors which can lead to occupational rhinitis in bakers are moulds and dust mites in grains (2), but these were not included in our study.

After the food industry, the second largest incidence of occupational rhinitis was in the textile industry. The typical aetiological agent was wool together with cotton and synthetic materials. Similar findings were published by Bousova et al., where textile antigens were responsible for up to $16 \%$ of rhinitis cases (22). However, it is very probable that prevalence of clinical rhinitis in textile workers might be considerably higher, because respiratory symptoms occurring after exposure to cotton and synthetic textiles are more based on irritation than on hypersensitivity (23).

Contrary to our expectations, we found low prevalence of OR in agricultural workers exposed to different plant and animal allergens. Moreover, there was only one case of OR caused by animal dander in our survey compared to $30 \%$ of cases from Finland (8).

Chemical substances were reported as a cause of both allergic and non-allergic irritant rhinitis in our study. Irritant rhinitis was diagnosed in subjects with rhinitis symptoms at the workplace but immunologic mechanisms were not determined.

Comparison of prevalence of occupational non-allergic irritant rhinitis among countries is hampered by the fact that it is not recognized as an occupational disease in all countries (27), as well as by lack of diagnostic standards. Unlike Slovakia, in the Czech Republic non-allergic rhinitis is not recognized as an occupational disease (27). However, irritant and non-IgE mediated rhinitis is recognized as an occupational disease in many countries worldwide (4). In our study, isocyanates did not play aetiological role in any of study subjects. In our previous study, however, isocyanates were a quite frequent aetiological factor of occupational asthma (24), reported by other studies as well $(25,26)$

Co-occurrence of bronchial asthma was found in $19 \%$ of subjects at the time of occupational rhinitis reporting or in later time period. Such cases were not reported as an independent occupational disease. However, in view of the fact that bronchial asthma is in terms of prognostics the most serious complication of rhinitis (28), the presence or absence of asthma influenced evaluation of compensation of social enforcement. In one study, the prevalence of bronchial asthma among patients with OR was reported $58.4 \%$, in case of high molecular weight agents even $72.2 \%$ (7). This points to a necessity of timely elimination of the patient from the workplace, since rhinitis often precedes bronchial asthma (29). Furthermore, interruption of exposition lowers the frequency of nasal symptoms and increases the quality of patient's life $(30,31)$.

The critical diagnostic method used for confirmation of causative associations of rhinitis with workplaces was in the most cases skin test. In some cases occupational rhinitis was reported on the basis of examination of specific IgE antibodies with both positive and negative skin tests of hypersensitivity to common inhalation allergens. Van Kampen et al. have shown that a high titer of specific IgE antibodies to flour among bakers is a good predictive marker of positive provocation test (32). In $18 \%$ of cases a diagnosis of occupational rhinitis was based on NPT, in $15 \%$ of patients a specific nasal test was performed by disc method at department of occupational medicine, and in 3\% an exposure test at the patient's workplace with the use of anterior active rhinomanometry was performed $(15,16)$. Similar, in the study by Bousova et al., a nasal provocation test was the crucial method in the diagnostic algorithm in $20 \%$ of patients (22). The introduction of nasal test into clinical practice in some regions in Slovakia was a significant step forward in the diagnostics of occupational rhinitis. NPT have in many cases greater diagnostic value compared with occupational history and skin tests. It is irreplaceable in cases of non IgE mediated rhinitis, where standard allergological examination methods can be used only for excluding the allergic origin of disease, but not for confirming of its occupational nature. Specific inhalation challenge is considered to be the gold standard for confirming occupational asthma. In contrast, there is no standard procedure to confirm OR (33). However, assessment of changes in clinical and functional parameters by means of objective and subjective methods during NPT represents the current recommended approach for confirming OR (6). In Slovakia, unlike in other countries, first NPT indicated for OR diagnosis was performed in 2003. Therefore, it has been the main diagnostic method only in quite small percentage of cases. On the contrary, previous publications from Finnish and Polish 
authors prove their long-term use of NPT in OR diagnosis (12, 34-36). In the Czech Republic, recommended procedures were elaborated in 2001 and also include NPT (27).

Our study has some limitations. The data were analyzed retrospectively for time period over 20 years. In such a long time span, the general opinions concerning the clinical importance of rhinitis of occupational and non-occupational aetiology rapidly evolved, not only in the Slovak Republic but all over the world $(17,18)$. This was reflected in the selection of diagnostic algorithms used during our study period. In the 1990's the diagnosis verification was based only on skin tests, occasionally utilizing positivity of specific IgE. In up to $5 \%$ of all cases OR was acknowledged exclusively on the basis of occupational history and hygienic workplace survey. Nowadays in our department, the specific NPT is the most important method in diagnostic algorithm in OR and is commonly used. However, there are no unified standards valid in the whole Slovak Republic. Our study is also limited by a relatively small number of patients due to the under-diagnosing of the illness. It is in a disagreement with the data from the Czech Republic, where in a similar period in the years 1992-2007, 398 cases of occupational rhinitis were reported. In addition, in 152 cases of bronchial asthma and rhinitis were reported simultaneously (37). However, in the Slovak Republic, when patients were diagnosed with both allergic rhinitis and asthma at the time of presentation, only asthma was reported as occupational disease. This is a potential source of underreporting of allergic rhinitis.

\section{CONCLUSION}

Allergic as well as non-allergic rhinitis ranks among the most common occupational health problems. Our study has proven the greatest occurrence of OR in food industry, textile industry and agriculture. Workers in these sectors should be considered as potentially endangered groups requiring preventive intervention. In case of showing rhinitis symptoms it is necessary to search for the occupational aetiology of the disease by the objective diagnostic methods. Since occupational rhinitis mostly precedes occupational asthma, it is necessary to eliminate the patient from the workplace and monitor lung functions.

\section{Conflict of Interest}

None declared

\section{Acknowledgements}

We thank to occupational physicians collaborating on this study: Dr. Darina Sauková, Dr. Róbert Vilček, Dr. Beáta Pivolusková, Dr. Pavol Moravčík, Dr. Anton Šišák

\section{REFERENCES}

1. Moscato G, Siracusa A. Rhinitis guidelines and implications for occupational rhinitis. Curr Opin Allergy Clin Immunol. 2009 Apr;9(2):110-5.

2. Siracusa A, Desrosiers M, Marabini A. Epidemiology of occupational rhinitis: prevalence, aetiology and determinants. Clin Exp Allergy. 2000 Nov;30(11):1519-34.

3. Hellgren J. Occupational rhinosinusitis. Curr Allergy Asthma Rep. 2008 May;8(3):234-9.
4. Siracusa A, Folletti I, Moscato G. Non-IgE-mediated and irritantinduced work-related rhinitis. Curr Opin Allergy Clin Immunol. 2013 Apr;13(2):159-66.

5. Sublett JW, Bernstein DI. Occupational rhinitis. Curr Allergy Asthma Rep. 2010 Mar;10(2):99-104.

6. EAACI Task Force on Occupational Rhinitis, Moscato G, Vandenplas O, Gerth Van Wijk R, Malo JL, Quirce S, Walusiak J, et al. Occupational rhinitis. Allergy. 2008 Aug;63(8):969-80.

7. Ameille J, Hamelin K, Andujar P, Bensefa-Colas L, Bonneterre V, Dupas $\mathrm{D}$, et al.; members of the rnv3p. Occupational asthma and occupational rhinitis: the united airways disease model revisited. Occup Environ Med. 2013 Jul;70(7):471-5.

8. Hytönen M, Kanerva L, Malmberg H, Martikainen R, Mutanen P, Toikkanen J. The risk of occupational rhinitis. Int Arch Occup Environ Health. 1997;69(6):487-90.

9. Ahman M, Söderman E. Serial nasal peak expiratory flow measurements in woodwork teachers. Int Arch Occup Environ Health. 1996;68(3):17782.

10. Eire MA, Pineda F, Losada SV, de la Cuesta CG, Villalva MM. Occupational rhinitis and asthma due to cedroarana (Cedrelinga catenaeformis Ducke) wood dust allergy. J Investig Allergol Clin Immunol. 2006;16(6):385-7.

11. Hellgren J, Eriksson C, Karlsson G, Hagberg S, Olin AC, Torén K. Nasal symptoms among workers exposed to soft paper dust. Int Arch Occup Environ Health. 2001 Mar;74(2):129-32.

12. Kujala V, Pirilä T, Niinimäki A, Reijula K. Latex-induced allergic rhinitis in a laboratory nurse. J Laryngol Otol. 1995 Nov;109(11):1094-6.

13. Marquès LI, Lara S, Abós T, Bartolomé B. Occupational rhinitis due to pepsin. J Investig Allergol Clin Immunol. 2006;16(2):136-7.

14. Schwartz HJ, Arnold JL, Strohl KP. Occupational allergic rhinitis reaction to psyllium. J Occup Med. 1989 Jul;31(7):624-6.

15. Perečinský S, Legáth L. Position of nasal exposure tests in diagnostics of occupational rhinitis. Prac Lek. 2009;61(1):21-6. (In Slovak.)

16. Varga M, Legáth L, Lepóris D. Exposure test in workers at risk of organic dusts. Ces Prac Lek. 2006;7(3):170-3. (In Slovak.)

17. Bousquet J, Van Cauwenberge P, Khaltaev N; Aria Workshop Group; World Health Organization. Allergic rhinitis and its impact on asthma. J Allergy Clin Immunol. 2001 Nov;108(5 Suppl):S147-334.

18. Bousquet J, Khaltaev N, Cruz AA, Denburg J, Fokkens WJ, Togias A, et al.; World Health Organization; GA(2)LEN; AllerGen. Allergic Rhinitis and its Impact on Asthma (ARIA) 2008 update (in collaboration with the World Health Organization, GA(2)LEN and AllerGen). Allergy. 2008 Apr;63 Suppl 86:8-160.

19. Smith TA, Patton J. Health surveillance in milling, baking and other food manufacturing operations - five years' experience. Occup Med (Lond). 1999 Apr;49(3):147-53.

20. Cullinan P, Cook A, Nieuwenhuijsen MJ, Sandiford C, Tee RD, Venables $\mathrm{KM}$, et al. Allergen and dust exposure as determinants of work-related symptoms and sensitization in a cohort of flour-exposed workers; a casecontrol analysis. Ann Occup Hyg. 2001 Mar;45(2):97-103.

21. Smith TA, Lumley KP. Work-related asthma in a population exposed to grain, flour and other ingredient dusts. Occup Med (Lond). 1996 Feb;46(1):37-40.

22. Boušová K, Krčmová I, Ranná D. Contribution of a nasal provocation test for the diagnostics of occupational allergic rhinitis. Prac Lek. 2006;58(2):57-61. (In Czech.)

23. Fishwick D, Fletcher AM, Pickering CA, Niven RM, Faragher EB. Respiratory symptoms and dust exposure in Lancashire cotton and man-made fiber mill operatives. Am J Respir Crit Care Med. 1994 Aug;150(2):441-7.

24. Perečinský S. Etiological factors of occupational asthma in the Eastern Slovakia region - retrospective study. Klin Imunol Alergol. 2013;23(4):912. (In Slovak.)

25. Lillienberg L, Andersson E, Janson C, Dahlman-Höglund A, Forsberg $\mathrm{B}$, Holm M, et al. Occupational exposure and new-onset asthma in a population-based study in Northern Europe (RHINE). Ann Occup Hyg. 2013 May;57(4):482-92.

26. Shin YS, Kim MA, Pham LD, Park HS. Cells and mediators in diisocyanate-induced occupational asthma. Curr Opin Allergy Clin Immunol. 2013 Apr;13(2):125-31.

27. Lebedová J, Fenclová Z, Boušová K, Brhel P. Occupational allergic rhinitis. Recommended procedures for practitioner [Internet]. Praha: ČLS JEP; 2001 [cited 2014 Jul 11]. Available from: http://www.cls.cz/ seznam-doporucenych-postupu. (In Czech.)

28. Seberová E. Message of nose to bronchi. Alergie. 2006;8(Suppl 1):35-8. (In Czech.) 
29. Karjalainen A, Martikainen R, Klaukka T, Saarinen K, Uitti J. Risk of asthma among Finnish patients with occupational rhinitis. Chest. 2003 Jan;123(1):283-8.

30. Castano R, Trudeau C, Castellanos L, Malo JL. Prospective outcome assessment of occupational rhinitis after removal from exposure. J Occup Environ Med. 2013 May;55(5):579-85.

31. Gerth van Wijk R, Patiwael JA, de Jong NW, de Groot H, Burdorf A. Occupational rhinitis in bell pepper greenhouse workers: determinants of leaving work and the effects of subsequent allergen avoidance on health-related quality of life. Allergy. 2011 Jul;66(7):903-8.

32. van Kampen V, Rabstein S, Sander I, Merget R, Brüning T, Broding HC, et al. Prediction of challenge test results by flour-specific IgE and skin prick test in symptomatic bakers. Allergy. 2008 Jul;63(7):897-902.

33. Nguyen SB, Castano R, Labrecque M. Integrated approach to diagnosis of associated occupational asthma and rhinitis. Can Respir J. 2012 NovDec;19(6):385-7.
34. Górski P, Krakowiak A, Pazdrak K, Palczynski C, Ruta U, Walusiak J. Nasal challenge test in the diagnosis of allergic respiratory diseases in subjects occupationally exposed to a high molecular allergen (flour). Occup Med (Lond). 1998 Feb;48(2):91-7.

35. Hytönen M, Sala E. Nasal provocation test in the diagnostics of occupational allergic rhinitis. Rhinology. 1996 Jun;34(2):86-90.

36. Palczynski C, Walusiak J, Ruta U, Gorski P. Nasal provocation test in the diagnosis of natural rubber latex allergy. Allergy. 2000 Jan;55(1):34-41.

37. Dlouhá B, Havlová D, Fenclová Z. Occupational allergic diseases in the Czech Republic. Alergie. 2008;10(Suppl 1):49-53. (In Czech.)

Received May 20, 2013 Accepted in revised form July 11, 2014 